\title{
Порядок направıения к месту отбывания наказания осужденных к аресту
}

В. С. ШАБАЛЬ - старший преподаватель кафедры уголовно-исполнительного права уголовно-исполнительного факультета Академии Министерства внутренних дел Республики Беларусь, кандидат юридических наук

Ре ферат

В статье анализируются проблемы в сфере направления к месту отбывания наказания осужденных к аресту в Республике Беларусь. На основе изучения уголовно-исполнительного законодательства делается вывод об отсутствии нормативного регулирования вопросов направления осужденных в арестные дома, понятия уклонения от отбывания наказания в виде ареста, а также порядка и условий привлечения к уголовной ответственности по ст. 414 Уголовного кодекса Республики Беларусь. Это обусловливает проблемы, связанные с нарушением принципа неотвратимости уголовной ответственности и практикой применения данного вида наказания, влечет в том числе рост рецидивной преступности, вплоть до тяжких и особо тяжких преступлений, посягающих на жизнь и здоровье человека.

На основе сравнительного анализа законодательства Республики Беларусь и Российской Федерации, регламентирующего порядок исполнения и отбывания наказания в виде ареста, отмечается схожесть правового регулирования данных общественных отношений и проблем в правоприменительной практике обеих стран.

Делается вывод о необходимости внесения изменений в Уголовно-исполнительный кодекс Республики Беларусь с целью устранения коллизий, связанных с исполнением наказания в виде ареста, а также проведения комплексного исследования исполнения наказания в виде ареста в Российской Федерации.

Ключевы е слова: осужденный; арест; арестные дома; уголовно-исполнительная инспекция; исполнение наказаний; направление осужденных к месту отбывания наказания.

12.00.08 - Уголовное право и криминология; уголовно-исполнительное право

\section{The procedure for sending sentenced to arrest to the place of punishment}

V. S. SHABAL - Senior Lecturer the Department of Penal Law of the Penal Department of the Academy of the Ministry of Internal Affairs of the Republic of Belarus, PhD. in Law 
Abstract

The article analyzes the problems in the direction of sentenced to arrest in the Republic of Belarus to the place of punishment. Based on the study of penal legislation it is concluded that there is no normative regulation of the issues of sending convicts to lockup houses, the concept of evading serving a sentence of arrest as well as the procedure and conditions for criminal prosecution under Art. 414 of the Criminal Code of the Republic of Belarus. This causes problems associated with the violation of the principle of the inevitability of criminal liability and the practice of applying this type of punishment, entailing among other things the growth of recidivism up to grave and especially grave crimes, encroaching on human life and health.

Based on a comparative analysis of the legislation of the Republic of Belarus and the Russian Federation, which regulates the execution and serving of punishment in the form of arrest, the similarity of legal regulation of these public relations and problems in the law enforcement practice of both countries is noted.

The conclusion is drawn about the need to amend the Penal Code of the Republic of Belarus in order to eliminate conflicts related to the execution of the sentence of arrest as well as conduct a comprehensive study of the execution of the sentence of arrest in the Russian Federation.

Key words: convicted; arrest; lockup houses; penal inspection; execution of sentences; sending convicts to the place of serving the sentence.

12.00.08 - Criminal law and criminology; penal law

В соответствии со ст. 48 Уголовного кодекса Республики Беларусь (УК РБ) одним из видов наказаний является арест, который заключается в содержании осужденного в условиях строгой изоляции на кратковременный срок. Несмотря на то что данное наказание существует уже 20 лет, многие вопросы, касающиеся его исполнения, не урегулированы по настоящее время, что представляется не совсем верным, так как все, что касается уголовной ответственности, должно быть четко регламентировано нормативными правовыми актами. Например, в настоящее время уголовно-исполнительным законодательством Республики Беларусь не в полной мере определен порядок направления к месту отбывания наказания осужденных к аресту, что порождает определенные проблемы при исполнении данного вида наказания.

Частью 4 ст. 58 Уголовно-исполнительного кодекса Республики Беларусь (УИК РБ) определено, что порядок направления к месту отбывания наказания осужденных к аресту устанавливается Министерством внутренних дел Республики Беларусь. При этом начальник территориального органа внутренних дел до того, как направить осужденного к месту отбывания наказания, может его заключить в следственный изолятор, для чего необходимо вынести постановление. То есть из анализа норм гл. 9 УИК РБ следует сделать вывод, что законодательством не определено следующее: кто в конечном итоге и как направляет осужденных в арестные дома; возможно ли самостоятельное следование осужденного к месту отбывания наказания; последствия неприбытия в арестный дом; понятие уклонения от отбывания наказания. При этом из анализа ч. 4 ст. 58 УИК РБ можно сделать вывод, что уполномоченными органами по реализации данной нормы являются территориальные органы внутренних дел, однако прямо об этом в кодексе не говорится (указано лишь то, что начальник отдела внутренних дел может поместить осужденного в следственный изолятор). В настоящее время направлением осужденных к аресту к месту отбывания наказания занимаются Департамент исполнения наказаний МВД Республики Беларусь (если осужденный содержится под стражей) либо уголовно-исполнительная инспекция территориального отдела внутренних дел (когда в период до осуждения обвиняемое лицо в следственный изолятор не помещалось).

По причине неурегулированности данных моментов возникают проблемы при реализации целей уголовной ответственности при применении наказания в виде ареста, что косвенно подтверждается статистическими данными. Так, за 2018-2019 гг. соотношение привлеченных к уголовной ответственности за уклонение от отбывания наказания в виде ареста по ст. 414 УК РБ и скрывшихся с места жительства осужденных к аресту составляет 1/107, то есть, несмотря на частые случаи, когда осужденные к аресту скрываются от отдела внутренних дел, суды привлекают граждан к уголовной ответственности по ст. 414 УК РБ лишь в единичных случаях.

Представляется, что такая ситуация складывается по причине неопределенности 
термина уклонения осужденных от отбывания наказания и порядка их направления в арестные дома. Органы уголовного преследования и суды, не имея действенной нормативной базы, не возбуждают уголовные дела по данной статье, закрепленной в уголовном законодательстве Республики Беларусь. В случае же задержания уклоняющегося осужденного его просто направляют к месту отбывания наказания под конвоем. C учетом всего вышесказанного возможна ситуация, когда лицо, совершившее преступление, может вовсе избежать наказания, поскольку в соответствии с п. 2 ч. 1 ст. 84 УК РБ оно может быть освобождено от наказания, так как истекут сроки давности (два года) исполнения приговора суда. В связи c неопределенностью понятия уклонения от отбывания наказания проблематично к нему применить ч. 2 ст. 84 УК РБ (в которой предусмотрено, что течение сроков давности приостанавливается, если осужденный уклоняется от отбывания наказания). Получается, что осужденному к аресту достаточно в течение двух лет после вынесения приговора скрываться для применения в отношении него п. 2 ч. 1 ст. 84 УК РБ, что часто становится реальностью.

Все это обусловливает необходимость определения понятия уклонения от отбывания наказания в виде ареста. В настоящее время из анализа ст. 414 УК РБ следует, что уклонение от отбывания наказания в виде ареста наступает лишь в том случае, если осужденный не был заключен под стражу в период вступления приговора в законную силу, так как в иных случаях может наступить уголовная ответственность за побег из арестного дома либо из-под стражи (ст. 413 УК РБ). При исполнении других наказаний, например такого вида ограничения свободы, как направление в исправительное учреждение открытого типа, предусмотрено вручение специального предписания о том, что необходимо в определенный срок выехать в учреждение по определенному адресу. В случае же осуждения к аресту этого не предусмотрено. Однако представляется, что аналогичный порядок должен действовать и при исполнении ареста. Если рассматривать ограничение свободы, то одним из элементов состава уклонения от отбывания наказания выступает отказ от вручения предписания, в котором в обязательном порядке указывается срок прибытия осужденного в исправительное учреждение открытого типа по конкретному адресу (если в срок не приезжает, то это тоже является нарушением). В связи с неопределенностью данных вопросов возникает ситуация, когда осужденный с момента вынесения приговора до вступления его в законную силу скрывается (при этом ему еще не было вручено предписание о выезде к месту отбывания наказания) и привлечь его к уголовной ответственности по данной статье УК РБ невозможно, так как ему официально не было сообщено, в каком арестном доме он обязан находиться в определенный срок. Данное положение является недопустимым, так как дает возможность избежать наказания преступнику, что является нарушением принципа неотвратимости уголовной ответственности, предусмотренного ч. 1 ст. 3 УК РБ.

В научно-практическом комментарии к ст. 414 УК РБ разъясняется, что уклонением будут являться «уклонение от получения предписания о выезде либо неприбытие к месту отбывания наказания без уважительных причин после получения предписания о выезде», а также «сокрытие осужденного с целью уклонения от отбывания наказания» [1, с. 887]. Однако это относится только лишь к такому виду наказания, предусмотренному УК РБ, как лишение свободы, поскольку данные выводы автором научно-практического комментария сделаны из анализа ст. 65 УИК РБ, в которой говорится о порядке направления осужденных к лишению свободы к месту отбывания наказания. Порядок же направления осужденных к аресту, как отмечалось ранее, не регламентирован в УИК РБ. Возможно, конечно, по аналогии использовать порядок, установленный для наказания в виде лишения свободы, однако в ч. 2 ст. 59 кодекса определено, что на осужденных к аресту ничего не распространяется, кроме условий, которые распространяются на осужденных к лишению свободы, содержащихся в тюрьме в условиях общего режима, что регламентировано ст. 125 УИК РБ. При этом отсылка к ст. 65 УИК РБ отсутствует. То есть процедура действий уполномоченных органов по направлению осужденных к аресту к месту отбывания наказания, порядок вручения предписания, последствия отказа от вручения предписания и т. д. не регламентированы законодательством.

Возникает также вопрос: каков юридический статус помещенного по постановлению начальника территориального отдела внутренних дел осужденного к аресту в следственный изолятор? Если приговор вступил в законную силу, то лицо имеет статус осужденного и в изоляторе отбывает на- 
казание в виде ареста. Если же приговор не вступил в законную силу, то в каком правовом статусе лицо содержится под стражей: заключенного под стражу или осужденного? Если это является мерой пресечения, то в ст. 126 Уголовно-процессуального кодекса Республики Беларусь (УПК РБ) регламентирован порядок применения данной меры пресечения (применяется к определенному кругу лиц, требуется санкция прокурора и т. д.). При этом в ст. З Закона Республики Беларусь от 16.06.2003 № 215-3 «О порядке и условиях содержания под стражей» определено, что одним из оснований содержания лиц под стражей является постановление (определение) о задержании. В ст. 5 данного закона в том числе установлено, что в следственном изоляторе могут содержаться не только заключенные под стражу, но и осужденные в случаях, предусмотренных УИК РБ, то есть начальник территориального отдела внутренних дел должен выносить постановление о задержании осужденного к аресту, которое в обязательном порядке необходимо санкционировать у прокурора. В этом случае неточность, существующая в законодательстве, будет устранена, и осужденный будет содержаться в следственном изоляторе на законных основаниях.

Для устранения вышеперечисленных коллизий необходимо внести изменения в УИК РБ с целью регламентации порядка направления осужденных к аресту к месту отбывания наказания, закрепления понятия уклонения от отбывания наказания в виде ареста, действий уполномоченных органов как при направлении, так и при установлении факта уклонения, возможности возмещения расходов в связи с розыском осужденного и пр.

Вопросы направления осужденных к месту отбывания других видов наказаний регулируется УИК РБ, а также нормативными правовыми актами МВД Республики Беларусь (в отношении осужденных к наказаниям, не связанным с изоляцией от общества, постановлением МВД от 15.01.2014 № 13, в отношении лишения свободы - постановлением МВД от 12.12.2005 № 389). Следует отметить, что в Республике Беларусь в отношении практически всех наказаний имеются свои нормативные правовые акты, регламентирующие процедуру направления осужденных в органы и учреждения, которые исполняют данные меры уголовной ответственности.

В отношении ареста схожего постановления не существует, несмотря на то что в ч. 4 ст. УИК РБ прямо указано, что порядок на- правления устанавливается МВД. 29 декабря 2016 г. министерство приняло постановление № 345 «Об утверждении Инструкции о порядке направления к месту отбывания наказания осужденных к аресту», которое не прошло обязательную юридическую экспертизу нормативных правовых актов, так как положения пунктов инструкции не соответствовали УИК РБ, в том числе ч. 4 ст. 58. Это было связано в основном с тем, что нормативные правовые акты МВД не могут устанавливать дополнительные правоограничения, не предусмотренные законом, в том числе и УИК РБ. По этим причинам 10 марта 2017 г. было принято постановление МВД № 57 «Об отмене постановления Министерства внутренних дел Республики Беларусь от 29 декабря 2016 г. № 345».

В случае внесения в УИК РБ нормы, регламентирующей общий порядок направления осужденных к аресту к месту отбывания наказания, содержание которой может быть аналогичным ст. 45, 65 данного кодекса, препятствие для ведомственного урегулирования данных процессов будет устранено, что позитивно повлияет на реализацию целей уголовной ответственности, в том числе предупреждения совершения нового преступления. При этом представляется, что с учетом того, что наказания в виде ареста и лишения свободы схожи по своей сути, необходимо предусмотреть порядок направления к месту отбывания наказания аналогичным направлению в исправительные учреждения. Это связано с тем, что лишение свободы и арест предполагают строгую изоляцию осужденных от общества (помещение в специализированные учреждения с определенным режимом) с ограничением социальных связей (в том числе с семьей)

Анализ УИК РФ позволяет сделать вывод, что проблемы, отраженные в данной статье применительно к законодательству Республики Беларусь, присущи и Российской Федерации. Так, в гл. 10 УИК РФ ничего не говорится о порядке направления осужденного к аресту к месту отбывания наказания, отсутствует понятие уклонения, да и в целом объем данной главы меньше, чем в УИК РБ. Стоит отметить, что в УК РФ вообще отсутствует статья за уклонение от отбывания наказания в виде ареста. Осужденный к аресту может совершить только побег, ответственность за который предусмотрена ст. 313 УК РФ. При этом аналогично законодательству Республики Беларусь порядок направления осужденных к лишению свободы подробно регламентирован ст. 75-76 УИК РФ. В соот- 
ветствии же со ст. 314 УК РФ наступает уголовная ответственность за то, что осужденный тем или иным способом уклоняется от того, чтобы отбывать такие виды наказаний, как ограничение свободы и лишение свободы. Возникает вопрос: почему в соответствии с УК РФ осужденные к ограничению свободы и лишению свободы могут допустить уклонение от отбывания наказания, а осужденные к аресту нет? Представляется, что данное положение не является правильным, так как позволяет определенной части преступников не нести уголовную ответственность за свои деяния.

Данная ситуация в законодательстве $\mathrm{Pe}$ спублики Беларусь и Российской Федерации сложилась по причине того, что наказание в виде ареста является относительно молодым и появилось с принятием действующих УИК РБ и УИК РФ. Однако в настоящее время такое положение вещей является недопустимым в правовых государствах, поэтому необходимо внести изменения в действующее законодательство.

Данную проблему возможно решить, если предусмотреть обязательное помещение судом осужденных к аресту в следственный изолятор после вынесения приговора. Однако данный вариант является не совсем перспективным, так как не позволяет суду дифференцированно подходить к вопросам применения мер пресечения в зависимости от личности виновного. В большинстве своем наказание в виде ареста применяется не за тяжелые преступления, поэтому содержать данных осужденных в изоляторе чаще всего нецелесообразно.

Таким образом, для реализации предложений, изложенных в данной статье, необходимо дополнить УИК РБ ст. 581', в которой предусмотреть следующее:

1. Порядок и сроки направления осужденных к аресту к месту отбывания наказания, если они содержатся в следственном изоляторе. Представляется, что срок должен составлять 10 дней с момента получения администрацией следственного изолятора соответствующих материалов из суда. Необходимо в течение этого срока предусмотреть право осужденного на свидание с близкими родственниками, а также обозначить, что саму процедуру направления должно определять ведомство, в подчинении которого находятся арестные дома, то есть МВД Республики Беларусь.

2. Если осужденный к аресту не находился под стражей в день вынесения приговора, то следует указать, что он может следо- вать в арестный дом самостоятельно за счет государства. Но в этом случае суд должен по согласованию с ДИН МВД Республики Беларусь еще в момент вынесения приговора обозначить время прибытия и конкретный арестный дом, в котором осужденный будет отбывать наказание. Территориальные органы внутренних дел должны вручать предписания о выезде. Представляется, что по аналогии с лишением свободы срок прибытия должен быть не менее трех суток с момента личного получения предписания осужденным.

3. В третьей части данной статьи необходимо указать то, что если осужденный в той или иной форме будет отказываться от получения предписания либо вовсе не приедет в арестный дом в срок, установленный ему органом внутренних дел, возможно его задержание на 15 суток (в обязательном порядке с санкции прокурора). В этот период времени должны устанавливаться причины, по которым конкретный осужденный к аресту уклонялся от наказания. Если органы внутренних дел не усмотрят уважительных причин, то им следует направить осужденного в арестный дом согласно наряду ДИН МВД Республики Беларусь.

4. Осужденный должен быть освобожден из-под стражи после того, как конвой доставит его в арестный дом.

5. Также следует обозначить, что если осужденный не прибывает в арестный дом, то именно территориальные органы внутренних дел объявляют его в розыск. Данная норма необходима, чтобы устранить неопределенность в том, кто будет заниматься поиском: подразделения милиции или органы и учреждения ДИН МВД Республики Беларусь.

6. Одновременно с этим следует указать, что в случае задержания осужденного он по постановлению начальника органов внутренних дел помещается в следственный изолятор, после чего либо решается вопрос о возбуждении уголовного дела за уклонение от отбывания наказания, либо он направляется в арестный дом.

7. Одной из составных частей исполнения наказания является порядок исчисления его срока, поэтому далее в ст. $58^{1}$ будет устанавливаться, что срок должен считаться с того момента, когда осужденного ставят на учет в арестном доме. В срок наказания должно засчитываться следующее: время нахождения в следственном изоляторе, время следования в арестный дом под конвоем. 
При расчете времени должно работать правило, аналогичное лишению свободы, когда один день содержания в следственном изоляторе под стражей соответствует одному дню в арестном доме. Одной из важных норм является то, что не включается в срок наказания время, когда осужденный самовольно отсутствовал на территории арестного дома свыше одного дня. Это связано с тем, что осужденным к аресту может быть предоставлен выезд за пределы учреждения в исключительных обстоятельствах.

В примечание к данной статье необходимо включить дефиницию близких родственников, которая в настоящее время содержится в примечании к ст. 59 УИК РБ.

Часть 4 ст. 58 УИК РБ и приложение к ст. 59 следует исключить в связи с тем, что данные нормы будут включены в ст. 58' УИК РБ.

Для определения понятия уклонения от отбывания наказания в виде ареста представляется возможным дополнить ст. 61 УИК РБ ч. 16-20.

В ч. 16 ст. 61 УИК РБ должна содержаться общая норма понятия уклонения, которая, по нашему мнению, включает в себя два элемента: 1) неприбытие в арестный дом в установленный предписанием срок; 2) невозвращение после краткосрочного выезда в арестный дом в установленный срок. В обоих случаях необходимо выяснять причины, по которым осужденный нарушил данные требования. Если имеются уважительные причины (например, заболевание и т. д.), уклонение от отбывания наказания не наступает.

Розыском осужденного к аресту, согласно ч. 17, в обоих вышеупомянутых случаях будут заниматься территориальные органы внутренних дел, что логично, так как осужденный как в одной, так и другой ситуации должен находиться в том районе, где расположен орган внутренних дел, который и будет объявлять его в розыск. Именно сотрудники территориальных органов внутренних дел должны владеть информацией как о возможном месте нахождения беглого осужденного, так и о круге его общения, что также способствует его поиску.

В ч. 18 ст. 61 УИК РБ постулируется, что в случае задержания осужденного в тех ситуациях, которые обозначены в ч. 17, его необходимо помещать в следственный изолятор либо изолятор временного содержания для проведения неотлагательных мероприятий как по выяснению причин, по которым он допустил уклонение, так и для возбуждения уголовного дела и проведения необходимых следственных действий.

Направлять материалы для осуществления уголовного преследования за уклонение в зависимости от ситуации будут следующие органы и учреждения: 1) в случае если осужденный не прибыл в учреждение после вынесения приговора - уголовно-исполнительная инспекция по месту нахождения суда; 2) в случае если осужденный не вернулся в арестный дом после выезда - администрация арестного дома (ч. 19).

Задерживать осужденного к аресту, если имеется уклонение от отбывания наказания, следует органу внутренних дел по месту жительства осужденного в обязательном порядке с санкции прокурора на срок не более тридцати суток. В связи с тем, что розыскные мероприятия предполагают определенные финансовые затраты, следует предусмотреть возможность удержания с осужденного денежной суммы, которую потратили уполномоченные органы на его поиск и задержание. При этом размер денежной суммы должен быть не произвольным, а установленным в нормативных правовых актах Совета Министров Республики Беларусь (ч. 20).

Представляется, что аналогично Республике Беларусь вопросы, рассмотренные в данной статье, требуют детального изучения и в Российской Федерации в целях последующей регламентации на законодательном уровне порядка исполнения наказания в виде ареста.

\section{СПИСОК ЛИТЕРАТУРЫ}

1. Уголовный кодекс Республики Беларусь: научно-практический комментарий / под редакцией В. М. Хомича, А. В. Баркова, В. В. Марчука. - Минск : Нац. центр правовой информ. Респ. Беларусь, 2019. - 1000 с. ISBN 978-985-6739-60-9.

\section{REFERENCES}

1. Homich V. M., Barkov A. V., Marchuk V. V. (red.) Ugolovnyj kodeks Respubliki Belarus': nauchno-prakticheskij kommentarij [The Criminal Code of the Republic of Belarus: Scientific and Practical Commentary]. Minsk, 2019. 1000 p. (In Russ.). 